Article

\title{
An Ultra-Wideband Bandpass Filter with a Notch Band and Wide Upper Bandstop Performances
}

\author{
Min-Hang Weng ${ }^{1}$, Che-Wei Hsu ${ }^{2}$, Siang-Wen Lan ${ }^{3}$ and Ru-Yuan Yang ${ }^{2, *}$ \\ 1 School of Information Engineering, Putian University, Putian 351100, China; hcwweng@gmail.com \\ 2 Graduate Institute of Materials Engineering, National Pingtung University of Science and Technology, \\ Pingtung County 912, Taiwan; namiemayday@gmail.com \\ 3 Microelectronics and Department of Electrical Engineering, National Cheng Kung University, \\ Tainan 701, Taiwan; s907952271@gmail.com \\ * Correspondence: ryyang@mail.npust.edu.tw; Tel.: +886-8-770-3202 (ext. 7555); Fax: +886-8-774-0552
}

Received: 20 October 2019; Accepted: 4 November 2019; Published: 8 November 2019

\begin{abstract}
This paper presents an ultra-wideband bandpass filter (UWB-BPF) with a notch band and a wide upper stopband. Two pairs of half-wavelength high-impedance line resonators tightly and strongly coupled to the input/output lines are used to provide the wideband responses. The first UWB responses of 3.4-5.0 GHz and the second UWB of $6.0-10.0 \mathrm{GHz}$ are designed independently first and then combined together for the application of a direct-sequence ultra-wideband bandpass (DS-UWB) system. Without using any extra bandstop structure, a notch band at $5.2 \mathrm{GHz}$ can be obtained. The fabricated UWB-BPF with a compact circuit size exhibits good passband performances including insertion losses of $1 \pm 0.3$ and $2 \pm 0.4 \mathrm{~dB}$ for first and second passbands, respectively, a high isolation at $5.2 \mathrm{GHz}$ with an attenuation level of $22.7 \mathrm{~dB}$, and wide upper stopband responses from $11 \mathrm{GHz}$ to $19 \mathrm{GHz}$, simultaneously. The measured results also exhibit good agreement with the simulated results.
\end{abstract}

Keywords: ultra-wideband; bandpass filter; half-wavelength resonator; insertion loss

\section{Introduction}

In recent years, multi-functional mobile wireless communication systems have been developed rapidly. For example, since February 2002, the U.S. Federal Communications Commission (FCC) has established the ultra-wideband (UWB) range from 3.1 to $10.6 \mathrm{GHz}$, used for imaging systems, vehicular radar systems, communication and measurement systems, etc. [1]. Due to advantages of low power consumption and high data transmission rate, UWB applications attract great attention. The bandpass filters (BPFs) are crucial devices in the communication system. Recently, both academia and industry have conducted many significant research activities exploring various UWB components and devices applied to a direct-sequence ultra-wideband (DS-UWB) system from 3.1 to $10.6 \mathrm{GHz}$ with a notch band at $5.7 \mathrm{GHz}[2,3]$.

In the past, several UWB-BPF design methods have been proposed [4-16]. In [4], the steppedimpedance resonator (SIR) was used to effectively obtain the wideband performance by controlling the spurious frequencies. However, the structure of the SIR suffered from design complexity, especially in the analysis of resonant frequencies. In [5], the multiple-mode resonator (MMR) was used for a UWB filter with good in-band and out-of-band performances, but revealed a large circuit size and insertion loss. In [6], the asymmetric stepped-impedance resonator (ASIR) was first presented to achieve the UWB performance with a wide stopband and high selectivity. However, the design of ASIRs still suffered from design complexity. In [7,8], the defect ground structure (DGS) was used in the UWB design; however, the DGS would usually destroy the signal integrality. In [9-11], wideband 
BPFs with notched bands were designed using different open/shorted stub-loaded resonators. In [12], a wideband bandpass filter was proposed by means of split circular rings and rectangular stubs. However, the bandwidth was not large enough and the notched band was not provided. In [13], a wideband bandpass filter was reported using a multi-layer structure; however, the design procedure and the device structure were complex. In [14], a wideband BPF was directly designed by using composite series and shunt resonators. In $[15,16]$, a wideband BPF was realized using multiple-mode split-ring resonators in a waveguide cavity. However, it is still a challenge to design a UWB-BPF without using a complex design process and structure to achieve a notch band, good band isolation and wide stopband response, simultaneously.

In this paper, we developed a simple technique and structure to achieve a compact and highperformance UWB filter by using two half-wavelength high-impedance line resonators. The bandwidth is decided by estimating the image impedance $\mathrm{Zi}$ of a one-stage coupled line. A notch band at $5.2 \mathrm{GHz}$ can be provided, without using any extra bandstop structure, to avoid interference with the signals of the wireless local area network (WLAN) system. Moreover, with two open stubs, the designed filter achieved the characteristics of a wide stopband and a high band-edge attenuation rate, simultaneously. The designed BPF was fabricated and measured to verify the design concept.

\section{Design Procedure}

Figure 1 is the structure of the proposed UWB-BPF filter. This filter is mainly formed by using two pairs of half-wavelength high-impedance line resonators and the input/output lines. Two arms of the half-wavelength high-impedance line resonators are tightly parallel, coupled to the input/output lines, formed as the coupled lines, to obtain a strong coupling for creating a wideband response. The resonator at the right side is designed for the first UWB responses of $3.4-5.0 \mathrm{GHz}$ and the resonator at the left side is designed for the second UWB of 6.1-10.0 GHz. In this study, the proposed UWB-BPF is implemented on the $0.787 \mathrm{~mm}$-thick Duroid 5880 substrate having a dielectric constant $\varepsilon \mathrm{r}$ of 2.2, and a loss tangent of 0.0009. The full-wave electromagnetic (EM) simulation tool (IE3D) is used in the design [17]. The design procedure is illustrated in detail as the following.

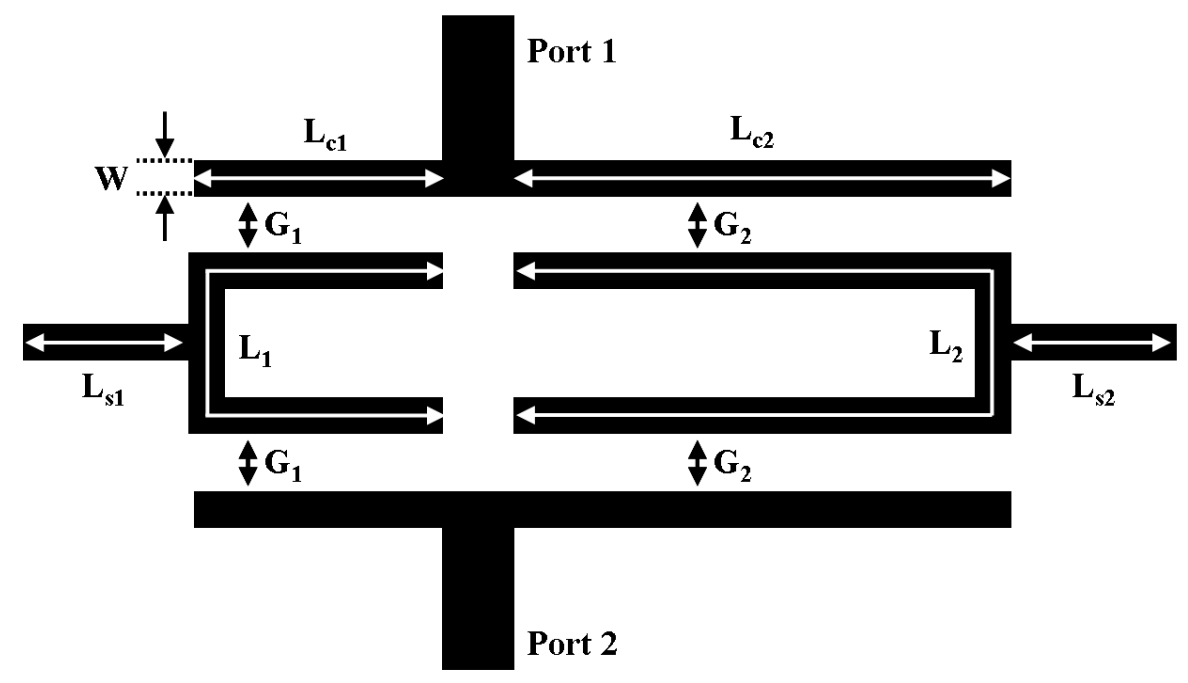

Figure 1. Structure of the proposed bandpass filter. ( $W=0.2 \mathrm{~mm}, \mathrm{G}_{1}=\mathrm{G}_{2}=0.2 \mathrm{~mm}, \mathrm{~L}_{1}=16.4 \mathrm{~mm}$, $\mathrm{L}_{2}=29.2 \mathrm{~mm}, \mathrm{~L}_{\mathrm{c} 1}=6.9 \mathrm{~mm}, \mathrm{~L}_{\mathrm{c} 2}=13.7 \mathrm{~mm}, \mathrm{~L}_{\mathrm{s} 1}=4.9 \mathrm{~mm}$, and $\left.\mathrm{L}_{\mathrm{s} 2}=4.4 \mathrm{~mm}\right)$.

\subsection{Step 1: Determining Centered Frequency of the Passband}

Firstly, the centered frequencies of the two passbands should be determined in accordance with the application of direct-sequence ultra-wideband bandpass (DS-UWB). The resonator is simply constructed by using a half guided-wavelength $(\lambda \mathrm{g} / 2)$ high-impedance line, where $\lambda \mathrm{g}$ is the guided-wavelength 
at the specific frequency. The line with high impedance, $158 \mathrm{ohms}$ in this case, is needed to have a strong coupling with a suitable gap to the input/output ports. To simplify the design, the impedance as well as the width of two resonators is the same. Figure 2 displays the resonant frequencies of the half-wavelength high-impedance line with different physical lengths. In the design, the required center frequencies of the first and second passbands are around 4.2 and $7.8 \mathrm{GHz}$, respectively. It is found that the resonator with a physical length of $29.2 \mathrm{~mm}$ excites a resonant peak at $4 \mathrm{GHz}$, responsible for the first passband at 3.4-5.0 GHz, and the resonator with the physical length of $14.8 \mathrm{~mm}$ excites a resonant peak at $8 \mathrm{GHz}$, responsible for the second passband at $6.0-10.0 \mathrm{GHz}$. Thus, $\mathrm{L}_{1}$ of $14.8 \mathrm{~mm}$ and $\mathrm{L}_{2}$ of $29.2 \mathrm{~mm}$ are firstly chosen for the first and second resonators, respectively.

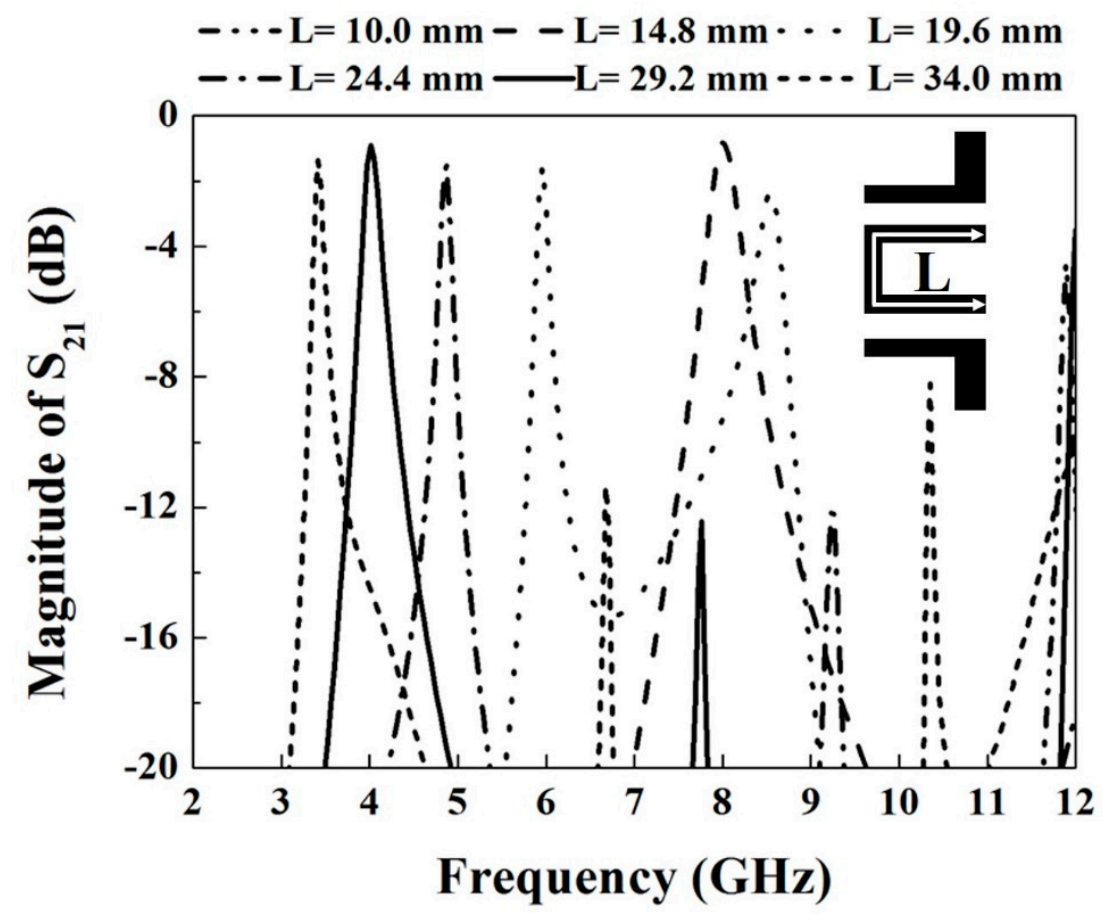

Figure 2. The resonant frequency of the half-wavelength high-impedance line with different physical lengths.

\subsection{Step 2: Forming the Wideband Response}

In general, the gap between the resonators and the input/output lines shall be as close as possible to obtain a wideband response. The resonators with high-impedance lines can avoid the gap smaller than the fabrication limit of the circuit board engraving machine. In previous research [18], the image impedance method was used to design a wideband bandpass filter, and the bandwidth of the passbands could be controlled by choosing different gaps of the coupled lines. The image impedance $\mathrm{Zi}$ is used to estimate the bandwidth of the coupled line and is expressed as [18]:

$$
Z_{i}=\sqrt{\left(Z_{0 e}-Z_{0 o}\right)^{2} \csc ^{2} \theta_{1}-\left(Z_{0 e}+Z_{0 o}\right)^{2} \cot ^{2} \theta_{1}}
$$

where $Z_{0 e}$ and $Z_{0 o}$ are the even and odd mode characteristic impedances, respectively, and $\theta_{1}$ is the electrical length of the coupled line. Moreover, by using the conformal mapping method, the $Z_{0 e}$ and $Z_{0 o}$ can be calculated as functions of the line width and coupling gap of the parallel coupled microstrip line [19]. Namely, as the dielectric constant ( $\varepsilon r$ ) and thickness (h) of the used substrate are identified, the $Z_{0 e}$ and $Z_{0 o}$ can be plotted as the design graphs versus different strip width $(\mathrm{W} / \mathrm{h})$ and coupling gaps $(G / h)$, as discussed and shown in Figure 2 [18]. Therefore, the required bandwidth of the coupled line can be calculated by selecting the image impedance $Z_{i}$, and then the $Z_{0 e}$ and $Z_{0 o}$ can be selected to achieve the desired image impedance $Z_{i}$. In this study, without using the design curve, a transmission 
line calculator of the full-wave EM simulator of Zeland IE3D software can be used to extract the $Z_{0 e}$ and $Z_{0 o}$ of the coupled line to match the dimension values [20].

Figure 3 shows the band responses with different coupling gaps $\left(G_{1}\right.$ and $\left.G_{2}\right)$ between the resonators and the input/output lines. It is noted that the harmonics mode at $7.8 \mathrm{GHz}$ of the first resonator, as shown in Figure 2, would also be combined with the resonant mode of the second resonator to form the second UWB passband response. Thus, the physical length of the second resonator shall be slightly tuned to satisfy the requirement of the second UWB passband response. After optimized simulation, the physical length $L_{1}$ is selected as $16.4 \mathrm{~mm}$ for the second passband at $6.0-10.0 \mathrm{GHz}$. The gaps $\mathrm{G}_{1}$ and $\mathrm{G}_{2}$ of $0.2 \mathrm{~mm}$ can achieve the desired bandwidths for the first and second passbands and are larger than the minimum operating range of the circuit board engraving machine.

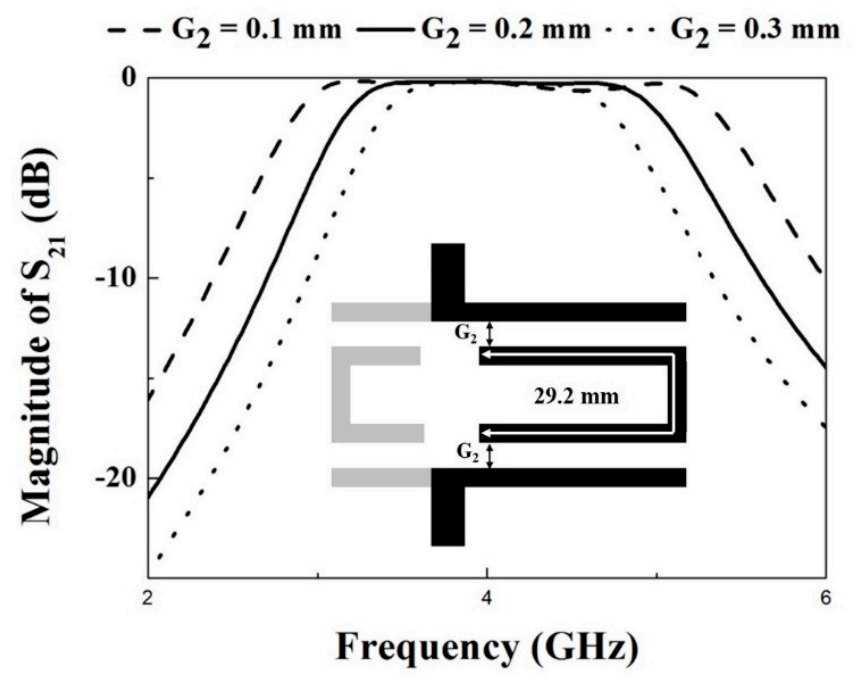

(a)

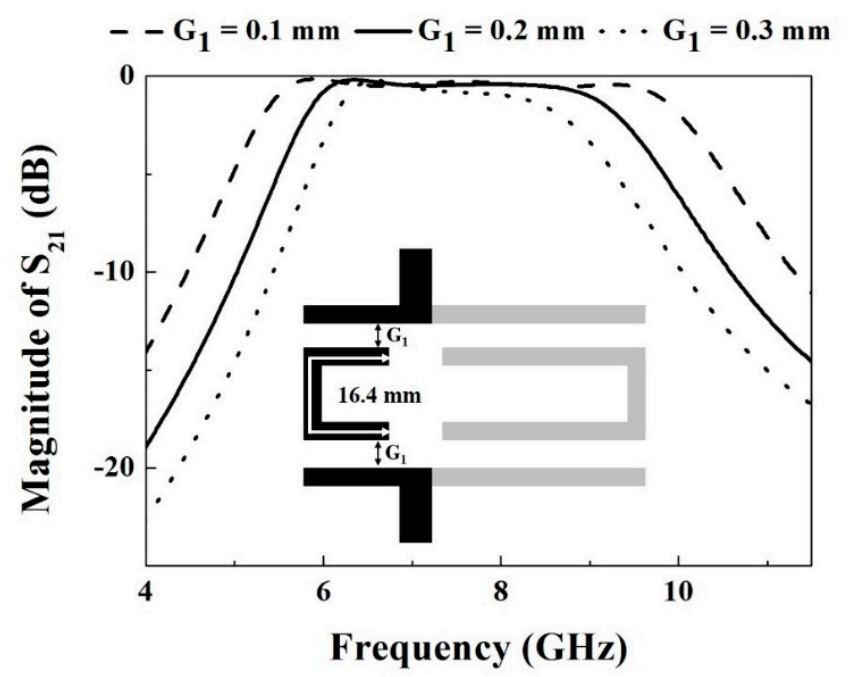

(b)

Figure 3. The band responses with different gaps between the resonators and the input/output lines. (a) first passband of $f_{1}=4 \mathrm{GHz}$ with $\mathrm{L}_{2}$ of $19.2 \mathrm{~mm}(\mathbf{b})$ second passband of $\mathrm{f}_{2}=8 \mathrm{GHz}$ with $\mathrm{L}_{1}$ of $16.4 \mathrm{~mm}$.

\subsection{Step 3: Combining Two UWB Responses}

In this step, the two UWB responses are combined to form the desired band requirements for the DS-UWB performance. Figure 4 shows (a) first passband and (b) second passband responses simulated by tuning the coupling gap of (a) $G_{1}$ (b) $G_{2}$, respectively. It is clearly observed that after combination, 
two UWB responses are not affected and are the same as those in Figure 3. Varying the coupling gap of $G_{1}$ and $G_{2}$ only slightly affects the second and first $U W B$ response, respectively. Thus, the coupling gaps $G_{1}$ and $G_{2}$ are obtained as $0.2 \mathrm{~mm}$ for the proposed filter design. Moreover, a notch band, namely, a stopband at $5.2 \mathrm{GHz}$ can be obtained naturally without using any extra bandstop structure, since the two wide passbands are individually formed and controlled. Namely, the frequency and attenuation of this stopband can be determined easily by controlling the upper band edge of the first wide band and the lower band edge of the second wide band in this design. Due to this notch band, the interference with the signals of the WLAN system can be avoided.

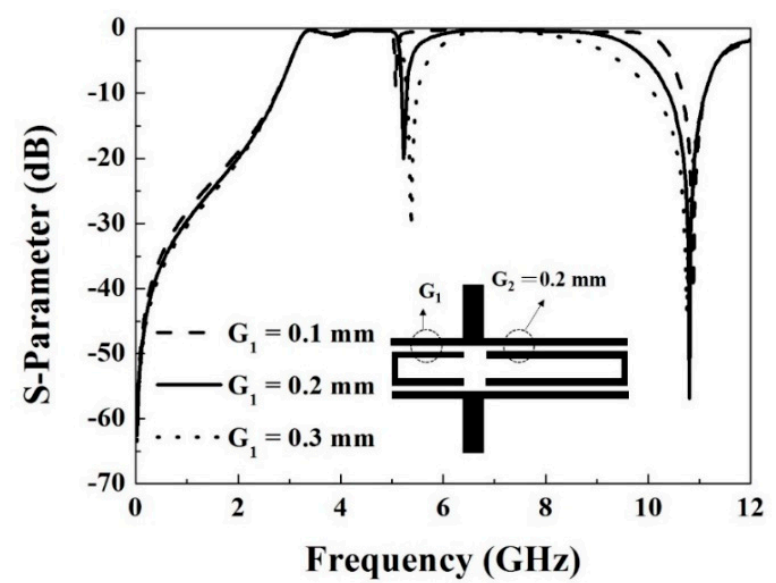

(a)

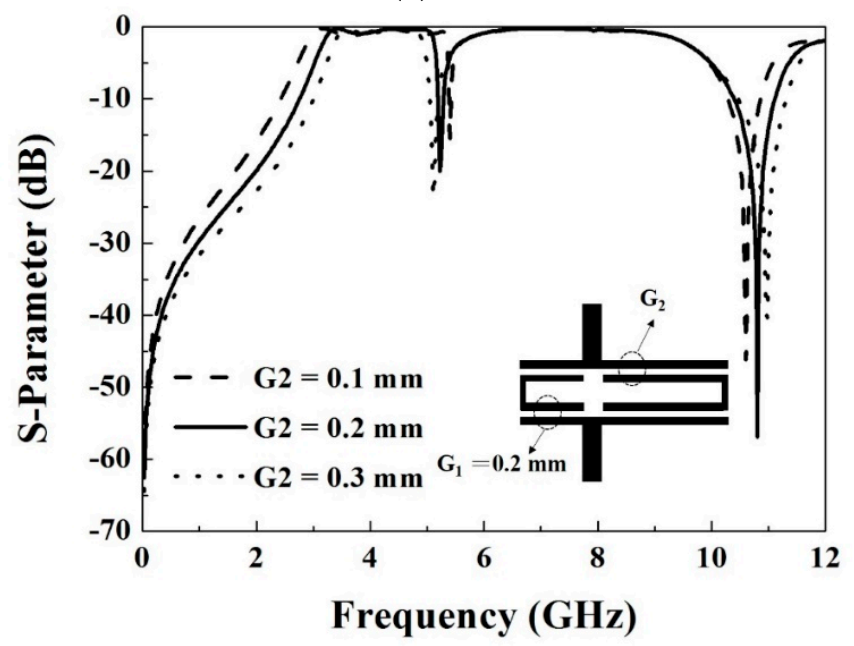

(b)

Figure 4. (a) First passband and (b) second passband responses simulated by tuning the coupling gap of $(\mathbf{a}) \mathrm{G}_{1}$ and $(\mathbf{b}) \mathrm{G}_{2}$, respectively $\left(\mathrm{W}=0.2 \mathrm{~mm}, \mathrm{~L}_{1}=16.4 \mathrm{~mm}, \mathrm{~L}_{2}=29.2 \mathrm{~mm}, \mathrm{~L}_{\mathrm{c} 1}=6.9 \mathrm{~mm}\right.$, $\mathrm{L}_{\mathrm{c} 2}=13.7 \mathrm{~mm}, \mathrm{~L}_{\mathrm{s} 1}=4.9 \mathrm{~mm}$, and $\mathrm{L}_{\mathrm{s} 2}=4.4 \mathrm{~mm}$ ).

\subsection{Step 4: Forming the Transmission Zeros}

As shown in Figure 4, the higher band of the designed UWB filter is poor and shall be improved. In order to extend the stopband region, two uniform open stubs are simply added to suppress the undesired spurious responses. It is known that the symmetrical plane of the half-wavelength high-impedance line shows a virtual ground characteristic [14]. Therefore, a wide stopband region could be achieved by tapping open stub loads at the symmetrical plane of the two half-wavelength high-impedance lines to form the transmission zeros. With the adoption of two tapped open stubs, the attenuation poles are located near the passband and the two passband performances are not affected, as shown in Figure 5. These two tapped open stubs with $\mathrm{L}_{\mathrm{s} 1}=4.9 \mathrm{~mm}$ and $\mathrm{L}_{\mathrm{s} 2}=4.4 \mathrm{~mm}$ are 
regarded as the quarter-guided wavelength resonators at $10.85 \mathrm{GHz}$ and $12.42 \mathrm{GHz}$ to suppress the undesired spurious responses, respectively.

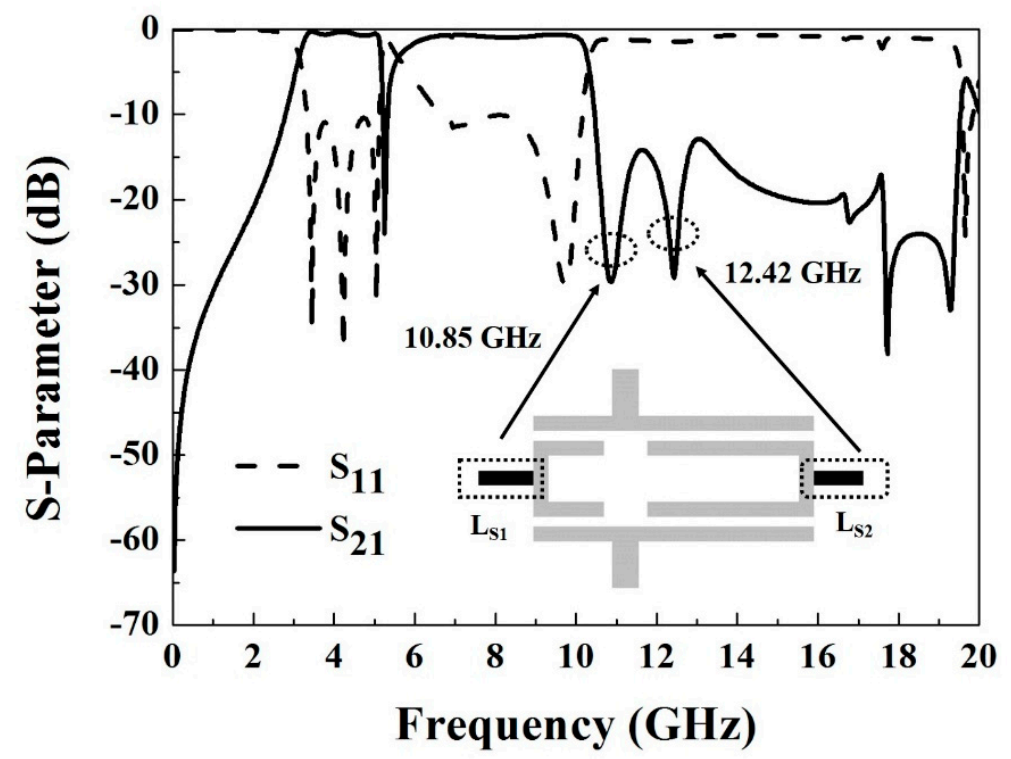

Figure 5. Frequency responses of the designed filter with two added open stubs.

Current distributions are used to confirm the resonant conditions of this UWB filter [1]. Figure 6a shows the simulated current distributions at the center frequencies of two passband responses, namely at 4 and $8 \mathrm{GHz}$. As discussed in Step 2, the strong coupling effect of the half-wavelength high-impedance line with narrow coupling gap $\left(\mathrm{G}_{1}\right.$ and $\left.\mathrm{G}_{2}\right)$ is used to excite the two ultra-wideband responses. Therefore, most current energy is absorbed by these resonators, thus creating a two-coupling path to excite two passband responses. Figure $6 \mathrm{~b}$ shows the simulated current distributions of the filter at the frequencies of the transmission zeros. As discussed in Step 4, when the tapped open stubs are regarded as the quarter-wavelength resonator, the transmission zeros are also created. Obviously, two tapped open stubs absorb, relatively, a lot the current energy, and the energy of the two half-wavelength high-impedance lines is not enough to excite a response, even with narrow coupling gaps $\left(G_{1}\right.$ and $\left.G_{2}\right)$, thus forming transmission zeros at $10.85 \mathrm{GHz}$ and $12.42 \mathrm{GHz}$.
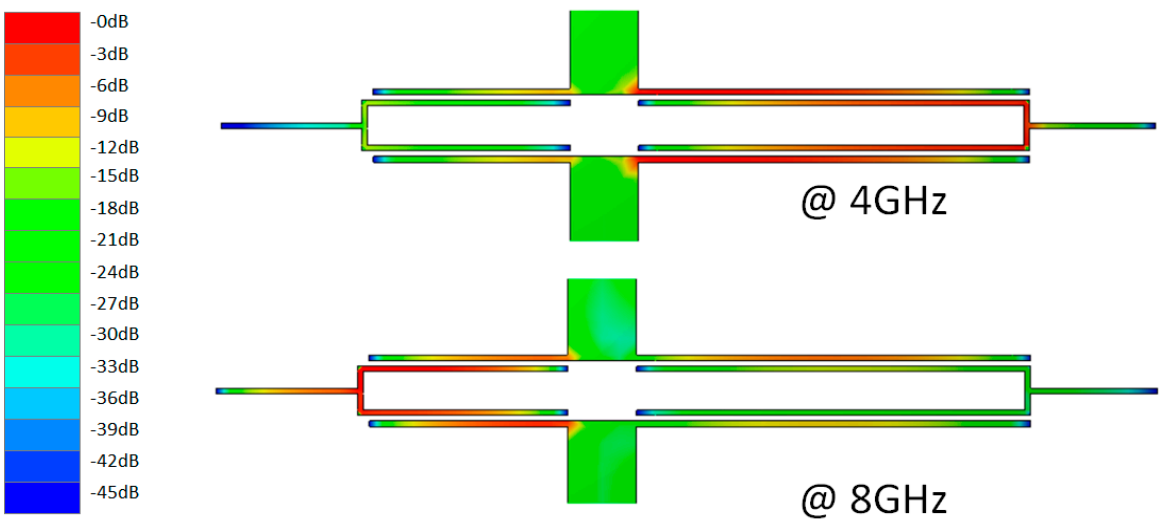

(a)

Figure 6. Cont. 

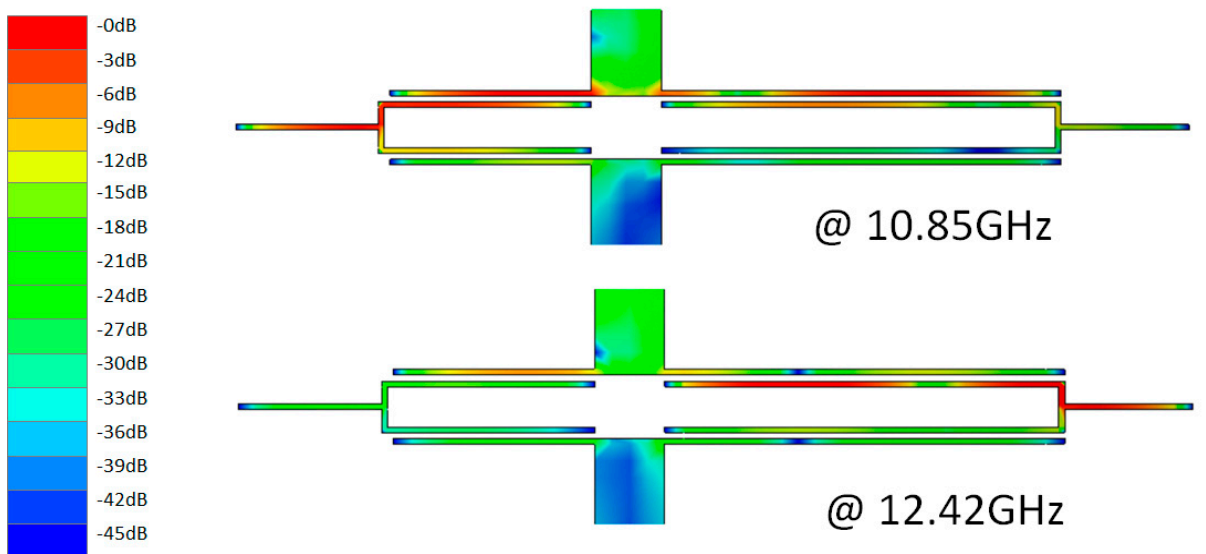

(b)

Figure 6. Current distributions of (a) the center frequencies of two wide bands, and (b) the frequencies of the transmission zeros.

\section{Experimental Results}

The designed UWB-BPF was fabricated by using an engraving machine, which can achieve the smallest line width and line gap of $0.15 \mathrm{~mm}$. The fabricated filter is measured by the HP8510C Network Analyzer after the standard short/open/load/through calibration. Figure 7 is the simulated and measured frequency responses of the fabricated UWB-BPF, with a picture of the fabricated filter inserted. The proposed UWB-BPF has a whole size of $32.3 \times 13 \mathrm{~mm}^{2}$, namely, around $0.70 \lambda \mathrm{g} \times 0.28 \lambda \mathrm{g}$, where $\lambda \mathrm{g}$ is the guided-wavelength at $5 \mathrm{GHz}$. For the first passband, a low insertion loss of $1 \pm 0.3 \mathrm{~dB}$ and a fractional bandwidth (FBW) of about $42 \%$ are obtained. For the second passband, a low insertion loss of $2 \pm 0.4 \mathrm{~dB}$ and a fractional bandwidth of about $58 \%$ are obtained. The transmission zeros appear at $10.85 \mathrm{GHz}$ and $12.42 \mathrm{GHz}$ to form a wide stopband region from $11 \mathrm{GHz}$ to $19 \mathrm{GHz}$, with a rejection level larger than $12 \mathrm{~dB}$. Also, due to the appearance of the transmission zero around $10.85 \mathrm{GHz}$, the upper band edge shows a high attenuation rate of $60 \mathrm{~dB} / \mathrm{GHz}$. Moreover, due to individual excitation of the two wide passbands, a notch band at $5.2 \mathrm{GHz}$ is obtained, thus achieving a high passband isolation with an isolation level of $22.7 \mathrm{~dB}$ without using extra bandstop structure and avoiding the interference with the signals of the WLAN system. The measured results are slightly different than the simulated results in the higher band, resulting from the material variation of the substrate.

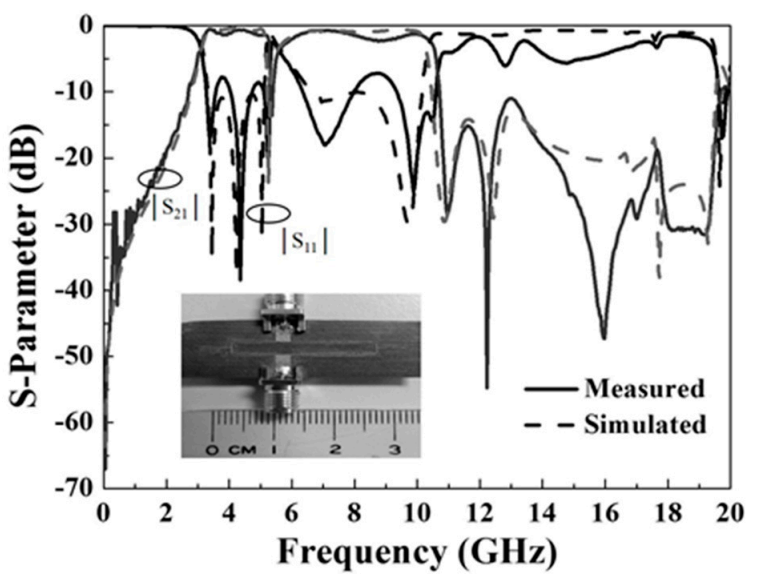

Figure 7. Simulated and measured frequency responses of the fabricated UWB-BPF. Inserted is the photograph of the filter. 
Measuring the deviation in the group delays across the two passbands of the proposed filter is necessary to quantify the level of distortion introduced by the designed filter [5]. Figure 8 shows the group delay of the measured results in the (a) first passband and (b) second passband. The group delays for two passbands are similar and exhibit a small varying range from 0.15 to $0.75 \mathrm{~ns}$. The measured results actually verify the possibility of the proposed design procedure.

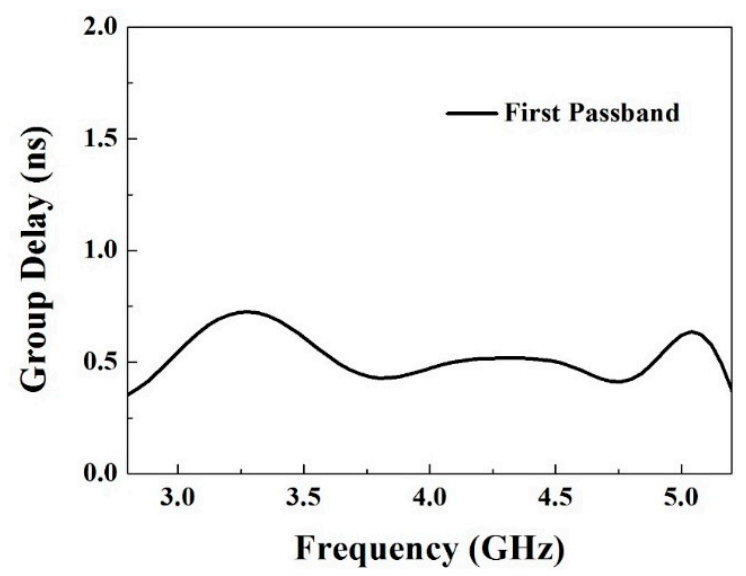

(a)

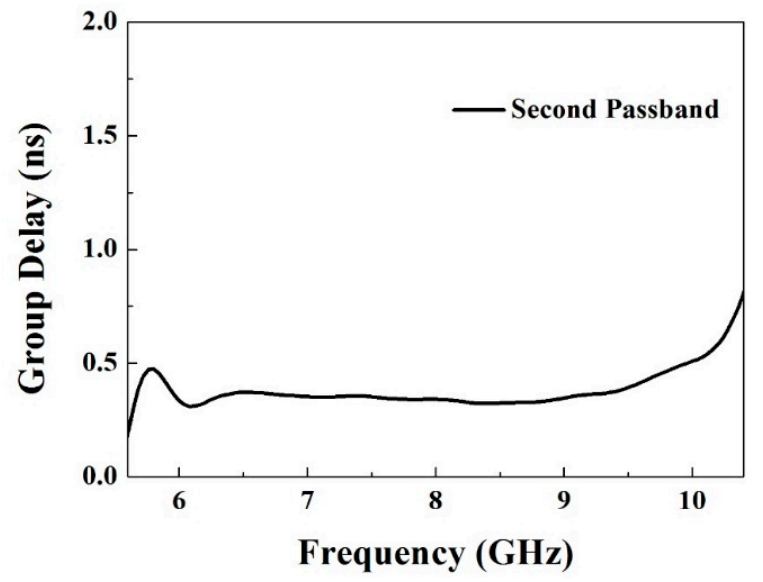

(b)

Figure 8. Group delays of the measured results in the (a) first passband and (b) second passband.

Table 1 shows the comparison of the designed filter with some published wideband BPFs. It is clear that the proposed design offers several advantages such as the appearance of the notched band and the wide stopband as well as the higher attenuation rate near the upper band edge compared to the previous reported work. Moreover, the proposed design has a very simple structure without requiring any defected ground area. Thus, the proposed UWB-BPF shows a good potential for the application of DS-UWB system.

Table 1. Comparison of filter performances of the proposed filter with the previous published works.

\begin{tabular}{|c|c|c|c|c|c|c|c|}
\hline & Ref. [8] & Ref. [9] & Ref. [10] & Ref. [11] & Ref. [12] & Ref. [13] & This Work \\
\hline$|\mathrm{S} 11|(\mathrm{dB})$ & 12 & 13 & 14 & 11.7 & $>13$ & 15 & 10 \\
\hline 3-dB FBW (\%) & 100 & 110 & 45 & 107 & 80 & 100 & 100 \\
\hline Circuit Size $(\lambda \mathrm{g} \times \lambda \mathrm{g})$ & Unknown & $0.15 \times 0.12$ & $0.30 \times 0.10$ & $0.89 \times 0.46$ & $0.53 \times 0.43$ & $0.74 \times 0.42$ & $0.70 \times 0.28$ \\
\hline Number of notched band & 1 & 0 & 0 & 2 & 0 & 1 & 1 \\
\hline
\end{tabular}




\section{Conclusions}

In this paper, a UWB-BPF with a low insertion loss, high band isolation and a wide upper stopband was reported. A simple method and structure were presented to realize the proposed UWB filter by using two half-wavelength high-impedance line resonators. The two UWB performances in the 3.4-5.0 and $6.1-10.0 \mathrm{GHz}$ ranges are controlled individually and thus a notch band at $5.2 \mathrm{GHz}$ is achieved to avoid signal interference with the WLAN signals. With the adoption of two tapped open stubs, the attenuation poles are located near the passband to suppress undesired spurious responses, causing a wide upper stopband. The measured results agree with the simulated results, and actually verify the design concept.

Author Contributions: M.-H.W. contributed the design concept and wrote the paper, C.-W.H. and S.-W.L. simulated, fabricated and measured the filter, and R.-Y.Y. provided the design resource and advised the design procedure.

Funding: This research received no external funding.

Conflicts of Interest: The authors declare no conflict of interest.

\section{References}

1. Federal Communication Commission. Revision of Part 15 of the Commission's Rules Regarding Ultra-Wideband Transmission Systems; ET-Docket 98-153, FCC02-48; Federal Communication Commission: Washington, DC, USA, 2002.

2. Kim, C.H.; Chang, K. Ultra-wideband (UWB) ring resonator bandpass filter with a notched band. IEEE Microw. Wirel. Compon. Lett. 2011, 21, 206-208. [CrossRef]

3. Hao, Z.C.; Hong, J.S.; Parry, J.P.; Hand, D.P. Ultra-wideband bandpass filter with multiple notch bands using nonuniform periodical slotted ground structure. IEEE Trans. Microw. Theory Technol. 2009, 57, 3080-3088.

4. Hung, C.Y.; Weng, M.H.; Su, Y.K. Design of compact and sharp rejection UWB BPFs using interdigital stepped-impedance resonators. IEICE Electron. Lett. 2007, 90, 1652-1654. [CrossRef]

5. Wong, S.W.; Zhu, L. Implementation of compact UWB bandpass filter with a notch-band. IEEE Microw. Wirel. Compon. Lett. 2008, 18, 10-12. [CrossRef]

6. Chang, Y.C.; Kao, C.H.; Weng, M.H.; Yang, R.Y. Design of the compact wideband bandpass filter with low loss, high selectivity and wide stopband. IEEE Microw. Wirel. Compon. Lett. 2008, 18, 187-189. [CrossRef]

7. Song, Y.; Yang, G.M.; Geyi, W. Compact UWB bandpass filter with dual notched bands using defected ground structures. IEEE Microw. Wirel. Compon. Lett. 2014, 24, 230-232. [CrossRef]

8. Liu, J.B.; Ding, W.H.; Chen, J.H.; Zhang, A. New ultra-wideband filter with sharp notched band using defected ground structure. Prog. Electromagn. Res. Lett. 2019, 83, 99-105. [CrossRef]

9. Deng, K.; Feng, W. Wideband bandpass filter with multiple transmission zeros and compact size. Microw. Opt. Technol. Lett. 2016, 58, 2452-2455. [CrossRef]

10. Zhang, Z.C.; Liu, H. A ultra compact wideband bandpass filter using a quadmode stub-loaded resonator. Prog. Electromagn. Res. Lett. 2018, 77, 35-40. [CrossRef]

11. Li, Y.; Choi, W.W.; Tam, K.W.; Zhu, L. Novel wideband bandpass filter with dual notched bands using stub-loaded resonators. IEEE Microw. Wirel. Compon. Lett. 2017, 27, 25-27.

12. Choudhary, D.K.; Chaudhary, R.K. A compact via-less metamaterial wideband bandpass filter using split circular rings and rectangular stub. Prog. Electromagn. Res. Lett. 2018, 72, 99-106. [CrossRef]

13. Ji, X.C.; Ji, W.S.; Feng, L.Y.; Tong, Y.Y.; Zhang, Z.Y. Design of a novel multi-layer wideband bandpass filter with a notched band. Prog. Electromagn. Res. Lett. 2019, 82, 9-16. [CrossRef]

14. Li, Z.; Wu, K.L. Direct synthesis and design of wideband bandpass filter with composite series and shunt resonators. IEEE Trans. Microw. Theory Technol. 2017, 65, 3789-3800. [CrossRef]

15. Hameed, M.; Xiao, G.; Qiu, L.; Xiong, C.; Hameed, T. Multiple-mode wideband bandpass filter using split ring resonators in a rectangular waveguide cavity. Electronics 2018, 7, 356. [CrossRef]

16. Hameed, M.; Xiao, G.; Najam, A.I.; Qiu, L.; Hameed, T. Quadruple-mode wideband bandpass filter with improved out-of-band rejection. Electronics 2019, 8, 300. [CrossRef]

17. Zeland Software, Inc. IE3D Simulator; Zeland Software, Inc.: Fremont, CA, USA, 2002. 
18. Ye, C.S.; Su, Y.K.; Weng, M.H.; Hung, C.Y.; Tang, R.Y. Design of the compact parallel-coupled lines wideband bandpass filters using image parameter method. Prog. Electromagn. Res. 2010, 100, 153-173. [CrossRef]

19. Hong, J.-S.; Lancaster, M.J. Microstrip Filters for RF/Microwave Applications; Wiley: New York, NY, USA, 2001.

20. Pozar, D.M. Microwave Engineering, 4th ed.; Wiley: New York, NY, USA, 2012; ISBN 978-0-470-63155-3.

(C) 2019 by the authors. Licensee MDPI, Basel, Switzerland. This article is an open access article distributed under the terms and conditions of the Creative Commons Attribution (CC BY) license (http://creativecommons.org/licenses/by/4.0/). 